\title{
Immunological effects of donor lymphocyte infusion in patients with chronic myelogenous leukemia relapsing after bone marrow transplantation
}

F.A. Castro ${ }^{1,2}$,

P.V.B. Palma ${ }^{2}$,

F.R. Morais ${ }^{2}$ and

J.C. Voltarelli2,3

\author{
1Departamento de Análises Clínicas, Toxicológicas e Bromatológicas, \\ Faculdade de Ciências Farmacêuticas de Ribeirão Preto, Universidade de São Paulo, \\ Ribeirão Preto, SP, Brasil \\ ${ }^{2}$ Fundação Hemocentro de Ribeirão Preto, Ribeirão Preto, SP, Brasil \\ ${ }^{3}$ Departamento de Clínica Médica, Faculdade de Medicina de Ribeirão Preto, \\ Universidade de São Paulo, Ribeirão Preto, SP, Brasil
}

\section{Correspondence \\ J.C. Voltarelli \\ Fundação Hemocentro de Ribeirão Preto (FUNDHERP) \\ Av. Bandeirantes, 3900 \\ 14051-140 Ribeirão Preto, SP \\ Brasil \\ Fax: +55-16-3963-9309 \\ E-mail: jcvoltar@fmrp.usp.br}

Research supported by the Center for Research in Cell-Based Therapy (CTC/FAPESP/No. 9814247-6), FUNDHERP, FAEPA-HCFMRPUSP and CNPq (No. 351860/92-4).

Received February 20, 2003

Accepted September 2, 2003

\begin{abstract}
Allogeneic bone marrow transplantation (alloBMT) is the only curative therapy for chronic myelogenous leukemia (CML). This success is explained by the delivery of high doses of antineoplastic agents followed by the rescue of marrow function and the induction of graftversus-leukemia reaction mediated by allogeneic lymphocytes against host tumor cells. This reaction can also be induced by donor lymphocyte infusion (DLI) producing remission in most patients with CML who relapse after alloBMT. The immunological mechanisms involved in DLI therapy are poorly understood. We studied five CML patients in the chronic phase, who received DLI after relapsing from an HLAidentical BMT. Using flow cytometry we evaluated cellular activation and apoptosis, NK cytotoxicity, lymphocytes producing cytokines (IL-2, IL-4 and IFN- $\gamma$ ), and unstimulated (in vivo) lymphocyte proliferation. In three CML patients who achieved hematological and/or cytogenetic remission after DLI we observed an increase of the percent of activation markers on $\mathrm{T}$ and NK cells (CD3/DR, CD3/ CD25 and CD56/DR), of lymphocytes producing IL-2 and IFN- $\gamma$, of NK activity, and of in vivo lymphocyte proliferation. These changes were not observed consistently in two of the five patients who did not achieve complete remission with DLI. The percent of apoptotic markers (Fas, FasL and Bcl-2) on lymphocytes and CD34-positive cells did not change after DLI throughout the different study periods. Taken together, these preliminary results suggest that the therapeutic effect of DLI in the chronic phase of CML is mediated by classic cytotoxic and proliferative events involving $\mathrm{T}$ and NK cells but not by the Fas pathway of apoptosis.
\end{abstract}

Key words

- Chronic myelogenous

leukemia

- Donor lymphocyte infusion

- Immune system

- Bone marrow

transplantation 
Chronic myelogenous leukemia (CML) is a myeloproliferative disorder characterized by the presence of a cytogenetic marker, the Philadelphia $(\mathrm{Ph})$ chromosome, which derives from a reciprocal translocation between chromosomes 9 and 22, i.e., t (9;22) (q34;q11), and the resultant production of constitutively activated $b c r-a b l$ tyrosine kinase in pluripotent hematopoietic progenitor cells (1). The disease evolves along three clinical phases of increasing severity: chronic phase, accelerated phase and blastic phase (1). Therapies currently available for CML in the chronic phase are chemotherapy (hydroxyurea), interferon- $\alpha$ (IFN- $\alpha$ ), tyrosine kinase inhibitors (STI571; Gleevec), allogeneic bone marrow transplantation (alloBMT) and donor lymphocyte infusion (DLI) (1). Over the past 35 years, alloBMT has emerged as an effective and potentially curative therapy of a variety of lethal hematological malignancies including CML. In the chronic phase the disease-free survival at 5 years reaches $70 \%$ for allografted patients in most centers (2).

The curative potential of alloBMT could be partially explained by delivery of very high doses of antineoplastic agents followed by the rescue of marrow function and the occurrence of the graft-versus-leukemia (GVL) effect (3), which is mediated by immunocompetent donor cells contained in the graft. These cells exert antileukemic effects in a number of ways (3), but donor T cells could also induce graft-versus-host disease (GVHD), which is a major cause of transplant-related mortality (3).

Definite evidence for the GVL effect was provided when infusion of allogeneic lymphocytes (DLI) from the BMT donor alone induced complete remission in CML patients who relapsed after BMT (4). Clinical experience with BMT, DLI and experimental tests in vitro indicates that CML is particularly susceptible to immune response regulation (5-7). There are few in vivo longitudinal studies investigating the immuno- logical system of CML patients treated with DLI. In one of these studies, after $\mathrm{CD}^{+}$ lymphocyte infusion $\mathrm{T}$ cells from four CML patients expressed a restricted $\mathrm{T}$ cell receptor $\mathrm{V} \beta$ repertoire, which persisted for three months and coincided with the time of the cytogenetic response (8). In another study, Verfuerth et al. (9) showed an expansion of a few numbers of $T$ cell clonotypes after DLI and thus a restricted $\mathrm{T}$ cell repertoire diversity. These two studies suggest that an oligoclonal $\mathrm{T}$ cell response could be associated with the GVL effect after DLI in CML patients.

The mechanisms underlying the antileukemic activity of DLI in CML need to be better understood to improve the current results of CML treatment and help the design of more efficient and less toxic protocols of immunotherapy (10).

The aim of this study was to investigate effects of DLI on several immunological phenotypes and functions in CML patients who relapsed after HLA-identical related BMT. We evaluated immunological parameters pre- and post-DLI $(+11,+30,+60,+90$ and +365 days) in the peripheral blood mononuclear cells (PBMC) of five CML patients in the chronic phase, three men and two women with a median age of 37.8 years (range 36-42 years). The chronology and characteristics of the relapse and of DLI, including number of infusions, dose of $\mathrm{T}$ cells infused, GVHD occurrence, and chimerism studies are described in Table 1.

Patients were on regular follow-up at the Bone Marrow Transplantation Unit of the University Hospital of the School of Medicine of Ribeirão Preto, State of São Paulo, Brazil or of the Federal University of Rio Grande do Sul.

CML relapse was confirmed by the detection of the $\mathrm{Ph}$ chromosome in the bone marrow by cytogenetics and the $b c r-a b l$ rearrangement by RT-PCR.

This protocol was approved by the Ethics Committee of Hospital das Clínicas da Fa- 
culdade de Medicina de Ribeirão Preto, Universidade de São Paulo. After signing the informed consent form, $20 \mathrm{ml}$ heparinized blood and $5 \mathrm{ml}$ EDTA-anticoagulated blood were collected, PBMC were isolated by density gradient centrifugation on FicollHypaque (Sigma, St. Louis, MO, USA) (11) and the following tests were performed: natural killer (NK) cell activity (12), apoptotic and activation markers on $\mathrm{T}$ lymphocytes, NK cells and stem cells, percentage of lymphocytes producing cytokines (IL-2, IL-4 and IFN- $\gamma$ ) (13), and in vivo lymphocyte proliferation (14).

For cell immunophenotyping, surface labeling was performed by a direct fluorescence technique using monoclonal antibodies (Becton-Dickinson, San Jose, CA, USA), against human CD3, CD8, CD19, CD56, CD34, CD3/CD25, CD3/DR, CD3/DQ, CD56/DR, CD19/DR, CD3/CD95 (Fas-R), CD56/CD95, CD19/CD95, CD34/CD95, CD8/CD95L (FasL), CD56/CD95L, CD34/ CD95L, and CD34/Bcl-2. To detect intracellular Bcl-2 protein, mononuclear cells were permeabilized with FACS permeabilizing solution (Becton-Dickinson). Flow cytometry analyses were carried out with a FACSort equipment (Becton-Dickinson) using the Cellquest software. The results are reported as the percent of stained cells calculated from 10,000 events for all immunophenotypes and 50,000 cells for the CD34+ cell quantification, subtracted from the test background percentage.

NK activity against K562 target cells was assessed by a flow cytometry assay (12) using the DIO membrane dye (Molecular Probes, Eugene, OR, USA), to stain live K562 cells and propidium iodide (Sigma) nuclear dye to stain dead cells. The percent of specific lysis was calculated by the formula:

$$
\frac{\% \text { dead target cells }}{100-\% \text { (debris and fragments) }} \times 100
$$

NK activity is reported as $40 \%$ lytic units per $10^{7}$ cells.

The percent of lymphocytes producing IFN- $\gamma$, IL- 2 and IL-4 was determined on PBMC stimulated with $25 \mathrm{ng} / \mathrm{ml}$ phorbolmyristate-acetate and $1 \mu \mathrm{g} / \mathrm{ml}$ ionomycin in the presence or absence of $10 \mu \mathrm{g} / \mathrm{ml}$ brefeldine-A. All reagents were purchased from Sigma. For intracellular IL- 2 and IFN- $\gamma /$ IL-4 detection, cells were incubated for 24 and 4 $\mathrm{h}$, respectively. After incubation, cells were fixed, permeabilized and labeled with spe-

\begin{tabular}{|c|c|c|c|c|c|c|}
\hline Patient & BMT & Relapse post-BMT & DLI & Infused T cells & GVHD post-DLI & Chimerism after last DLI \\
\hline 1 & 10/8/1996 & $7 / 18 / 1997$ & $\begin{array}{l}\text { 1st 9/12/1997 } \\
\text { 2nd 9/28/1997 }\end{array}$ & $\begin{array}{l}\text { 1st } 1.0 \times 10^{8} / \mathrm{kg} \\
\text { 2nd } 1.7 \times 10^{8} / \mathrm{kg}^{*}\end{array}$ & $\begin{array}{l}\text { No } \\
\text { No }\end{array}$ & $86 \% X Y-H$ \\
\hline 2 & $4 / 25 / 1995$ & $7 / 14 / 1998$ & $\begin{array}{l}\text { 1st } 7 / 27 / 1998 \\
\text { 2nd } 11 / 14 / 1998 \\
\text { 3rd 3/30/1999 }\end{array}$ & $\begin{array}{l}1 \text { st } 1.0 \times 10^{7} / \mathrm{kg} \\
\text { 2nd } 1.8 \times 10^{8} / \mathrm{kg} \\
\text { 3rd } 6.7 \times 10^{8} / \mathrm{kg}\end{array}$ & $\begin{array}{c}\text { No } \\
\text { No } \\
\text { Day }+100\end{array}$ & $100 \% \mathrm{Ph}$ negative \\
\hline 3 & 11/1/1995 & 12/26/1996 & 1/7/1997 & $2.8 \times 10^{8} / \mathrm{kg}$ & No & $100 \%$ XY-D (CNS relapse) \\
\hline 4 & $5 / 5 / 2000$ & $9 / 1 / 2000$ & $1 / 31 / 2001$ & $2.1 \times 10^{8} / \mathrm{kg}$ & No & Not done \\
\hline 5 & 3/10/1997 & 9/9/1999 & $\begin{array}{l}\text { 1st } 11 / 17 / 1999 \\
\text { 2nd 2/14/2000 } \\
\text { 3rd 4/30/2000 }\end{array}$ & $\begin{array}{r}1 \text { st } 2.0 \times 10^{7} / \mathrm{kg} \\
2 \text { nd } 3.8 \times 10^{8} / \mathrm{kg} \\
3 \text { rd } 5.3 \times 10^{8} / \mathrm{kg}\end{array}$ & $\begin{array}{c}\text { No } \\
\text { No } \\
\text { Day }+130\end{array}$ & $100 \% X Y-D$ \\
\hline
\end{tabular}
cific antibodies (Becton-Dickinson). Analy-

Dates = month/day/year; BMT = bone marrow transplantation; CNS = central nervous system; $\mathrm{D}=$ donor; DLI = donor lymphocyte infusion; $\mathrm{GVHD}=$ graft-versus-host disease; $\mathrm{H}=$ host; $\mathrm{Ph}=$ Philadelphia chromosome

*Immunological studies performed after last DLI. 
ses were performed with a FACSort cytometer using the Cellquest software and the results are reported as percent of stained cells per 10,000 events and subtracted from the test background percentage.

In vivo mixed lymphocyte culture assay was performed by a modification of the standard mixed lymphocyte culture method. Briefly, 1 x $10^{5}$ mononuclear cells obtained from patients were cultured without stimulation in triplicate in trays for 6 days in a humidified atmosphere with $5 \% \mathrm{CO}_{2}$. On the fifth day, cultures were pulsed with $1 \mu \mathrm{Ci}$ of tritiated thymidine and further incubated for $20 \mathrm{~h}$ at $37^{\circ} \mathrm{C}$ in a humidified atmosphere with $5 \% \mathrm{CO}_{2}$. After harvesting the cells, total isotope incorporation was determined by scintillation counting in a $\beta$-counter.

Over the study period, three patients (Nos. 2, 4 and 5) achieved hematological remission (defined as a white blood cell count $<10$ x $10^{9} / 1$, platelets $<450 \times 10^{9} / 1,<5 \%$ circulating immature cells, and absence of organomegaly) and/or cytogenetic remission (defined as absence or 35-65\% of Ph-positive metaphases by cytogenetic analysis), but the other two patients (Nos. 1 and 3) did not achieve disease remission and died on days +83 and +98 post-DLI, respectively.

Clinical responses were associated with the infusion of larger cell doses and the occurrence of GVHD. However, immunological changes were observed earlier than GVHD. Chimerism after DLI was studied cytogenetically and showed a predominance of donor cells in one patient (No. 5) who responded and of host cells in one patient (No. 1) who did not respond. One patient (No. 3) with central nervous system relapse showed donor cells in the marrow.

Statistical differences among the five study periods (pre-DLI, $+11,+30,+60$ and +90 ) in the groups of patients who achieved hematological and/or cytogenetic remission (patients 2, 4 and 5) and patients without remission (patients 1 and 3) were analyzed by the Friedman test followed by the Dunn test for multiple comparisons. A P value $<0.05$ was taken as significant. All analyses were performed using Prism 2.01 software.

In the present study, we evaluated the effects of DLI as a therapeutic intervention on the immune system of five CML patients in the chronic phase, who relapsed after

Table 2. Immunological evaluation of chronic myelogenous leukemia patients after donor lymphocyte infusion treatment.

\begin{tabular}{|c|c|c|c|c|c|c|c|c|c|c|c|c|c|c|c|}
\hline \multirow[b]{3}{*}{ Parameter } & \multicolumn{15}{|c|}{ Study periods } \\
\hline & \multicolumn{5}{|c|}{+11 days } & \multicolumn{5}{|c|}{+30 days } & \multicolumn{5}{|c|}{+60 days } \\
\hline & 1 & 3 & 2 & 4 & 5 & 1 & 3 & 2 & 4 & 5 & 1 & 3 & 2 & 4 & 5 \\
\hline $\mathrm{CD} 8 / \mathrm{mm}^{3 *}$ & 0.8 & 0.9 & 0.7 & 0.9 & 1.3 & 0.8 & 1.0 & 0.9 & 1.5 & 1.7 & 1.0 & ND & 1.4 & 2.1 & 2.0 \\
\hline $\mathrm{CD} 56 / \mathrm{mm}^{3 *}$ & 0.2 & 0.2 & 0.2 & 0.2 & 0.2 & 0.2 & 0.2 & 0.3 & 0.5 & 0.3 & 0.2 & ND & 0.4 & 0.4 & 0.5 \\
\hline$\% C D 4^{\#}$ & 5.8 & 5.0 & 7.8 & 3.0 & 1.0 & 7.4 & 9.0 & 12.0 & 16.0 & 1.0 & 1.4 & ND & 26.0 & 24.0 & 2.0 \\
\hline$\% \mathrm{CD}^{\#}$ & 21.0 & 8.0 & 12.0 & 7.5 & 2.6 & 18.0 & 2.0 & 18.0 & 18.0 & 2.0 & 0.5 & ND & 16.0 & 8.0 & 1.0 \\
\hline$\% \mathrm{CD} 3 / \mathrm{DR}^{\#}$ & 0.3 & 0.4 & 1.2 & 0.7 & 4.5 & 0.4 & 0.0 & 2.4 & 7.7 & 8.3 & 0.3 & ND & 2.8 & 9.8 & 7.2 \\
\hline$\% \mathrm{CD} 3 / 25^{\#}$ & 1.1 & 0.1 & 2.0 & 3.3 & 4.5 & 0.1 & 0.0 & 8.6 & 6.3 & 9.4 & 0.0 & ND & 6.8 & 6.9 & 7.4 \\
\hline$\%$ CD56/DR & 5.7 & 0.0 & 1.8 & 3.0 & 3.0 & 10.0 & 0.0 & 5.8 & 0.5 & 3.6 & 0.2 & ND & 2.2 & 0.9 & 4.4 \\
\hline$\%$ of IL-2-producing lymphocytes ${ }^{\#}$ & 2.0 & 0.9 & 4.0 & 2.6 & 5.0 & 0.0 & 1.0 & 12.0 & 8.0 & 13.0 & 0.5 & ND & 18.0 & 8.0 & 15.0 \\
\hline$\%$ of IFN- $\gamma$-producing lymphocytes ${ }^{\#}$ & 0.1 & 1.1 & 2.0 & 6.0 & 5.0 & 0.9 & 1.3 & 6.0 & 9.0 & 10.0 & 0.1 & ND & 9.0 & 11.0 & 14.0 \\
\hline$\%$ of IL-4-producing lymphocytes ${ }^{\#}$ & 0.5 & 0.2 & 0.0 & 0.5 & 0.0 & 0.6 & 0.5 & 0.3 & 0.7 & 0.2 & 0.1 & ND & 0.0 & 0.4 & 0.5 \\
\hline
\end{tabular}

*Absolute number $\times 10^{3}$. \#Results are reported as percent of positive cells subtracted from the values obtained pre-donor lymphocyte infusion. $\mathrm{ND}=$ not determined. Increases in activation markers on lymphocyte surface (CD3/DR, CD3/25 and CD3/56) and in the intracellular production of IL-2 and IFN- $\gamma$ were statistically significant only in the group of patients who achieved remission after donor lymphocyte infusion (patients 2, 4 and 5; Friedman test followed by Dunn test for multiple comparisons). 
BMT. The immune system was investigated immunophenotypically (by determination of activation and apoptotic markers on T, B and NK cells) and functionally (by NK activity, production of cytokines and lymphocyte proliferation). We also monitored the expression of Bcl-2, Fas and FasL antigens on CD $34^{+}$stem cells. The results were associated with the achievement of a hematological and cytogenetic response.

The percent of activation markers on $\mathrm{T}$ and NK cells (CD3/DR, CD3/CD25 and CD56/DR, Table 2) showed a significant increase in patients who achieved remission post-DLI but not in patients who did not achieve remission. In the entire group of patients the percent values of cells positive for CD3/Fas, CD56/Fas, CD34/Fas, CD56/ FasL, CD8/FasL, CD34/Fas, CD34/DR, CD34/DQ, CD34/Bcl-2, CD19/DR, CD19/ Fas did not change after DLI therapy throughout the different study periods. On the basis of these results, apoptosis, through the FasFasL pathway, seems not to be involved in the antileukemic effect of DLI. In fact, Deininger et al. (15) and Ravandi et al. (16) reported that $\mathrm{Ph}$-positive progenitor cells are resistant to apoptosis (Fas-FasL pathway), providing a growth advantage to leukemic cells over normal cells. Interestingly, all patients presented a reversed CD4/CD8 cell ratio on day +11 post-DLI suggesting an involvement of CD8 $\mathrm{T}$ cells in the response against relapsing CML (Table 2).

NK activity tended to increase in all patients, but was statistically significant only in patients who achieved remission (Figure 1). These results agree with those reported by Pawelec et al. (17), who demonstrated a correlation between NK cell activation and elimination of bcr-abl-positive cells in vitro. Therefore, it seems that NK cell cytotoxicity plays a role in the antileukemic effector mechanism in CML, contributing to hematological and cytogenetic remission. Thus, the relationship between NK activity and the GVL effect mediated by DLI needs to be better

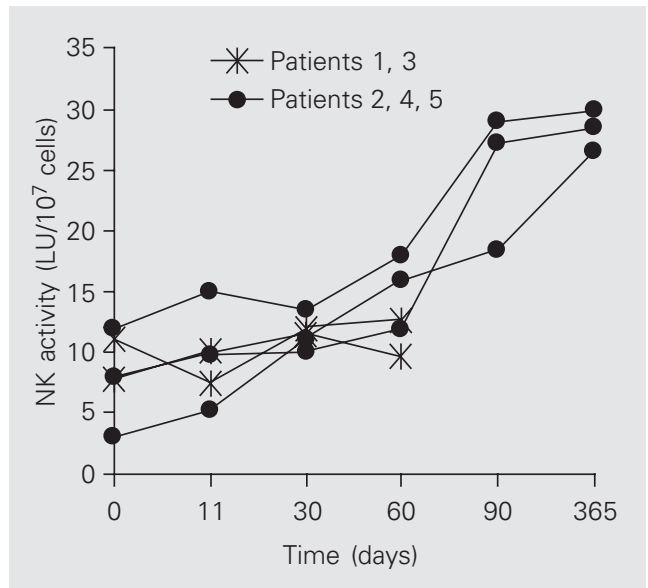

Figure 1. Natural killer (NK) cell activity in chronic myelogenous leukemia patients after donor lymphocyte infusion (DLI). NK activity is reported as $40 \%$ lytic units (LU) per $10^{7}$ cells. NK cytotoxicity increased significantly $(P<0.0009)$ in patients who achieved remission (numbers 2, 4 and 5) after DLI, but remained unchanged $(P>0.05)$ in patients 1 and 3 who did not respond to DLI (Friedman test followed by Dunn test for multiple comparisons). Note that the abscissa scale is not linear.

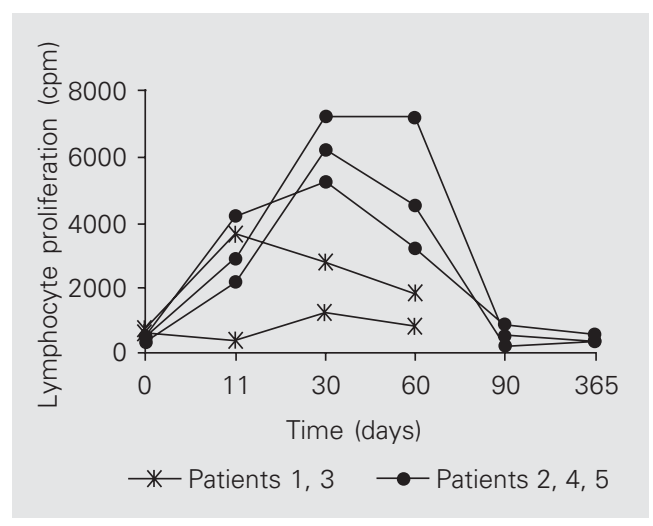

investigated.

Patients who presented a response to DLI treatment showed a statistically significant increase in the percent of lymphocytes capable of producing IL-2 and IFN- $\gamma$, in contrast to patients who maintained relapse (Table 2). These cytokines are involved in classic Th1 cell-mediated functions such as clonal expansion of cytotoxic $\mathrm{T}$ lymphocytes, macrophage activation, up-regulation of co-stimulatory and major histocompatibility complex molecules on antigen-presenting cells, $\mathrm{T}$ cell proliferation, and NK activation. IL-2 and IFN- $\gamma$ improve the interaction between host and donor cells and prevent the escape of leukemic cells from the immune system (18). In contrast, the percent of lymphocytes capable of producing IL-4, a Th2 cytokine, did not change over the study periods in any patient (Table 2).

In vivo lymphocyte proliferation tended to
Figure 2. Lymphocyte proliferation in chronic myelogenous leukemia patients after donor lymphocyte infusion (DLI). Proliferation is expressed as incorporated tritiated thymidine (cpm). Lymphocyte proliferation increased significantly $(P=0.0028)$ in patients who achieved remission (numbers 2, 4 and 5) after DLI treatment, but remained unchanged $(P>0.05)$ in patients 1 and 3 who did not respond to DLI (Friedman test followed by Dunn test for multiple comparisons). Note that the abscissa scale is not linear 
increase in all patients between days +11 and +60 , but this increase in proliferation was statistically significant only in patients 2,4 and 5 who achieved remission after DLI (Figure 2). This result fits the clinical observations that allogeneic $T$ cells are capable of generating tumor-specific immunity and could be used as immunotherapy for CML (19). In fact, the efficacy of allogeneic donor lymphocytes based on histocompatibility differences between donors and recipients is essential to obtain remission in CML patients (20).

Taken together, these results suggest that DLI could induce a GVL effect and upregulate the immune response in CML patients. Our preliminary observations also agree with previous clinical studies indicating that an allogeneic immune response con- tributes to the control of CML after BMT relapse and support the further use of DLI associated with other CML therapies such as IFN- $\gamma$, tyrosine-kinase inhibitors and alloBMT. If confirmed in a study with more patients, these data will provide important information to design effective immunotherapies for other malignancies such as multiple myeloma, lymphoma and acute leukemias.

\section{Acknowledgments}

We are grateful to the Bone Marrow Transplantation Unit of the Federal University of Rio Grande do Sul, specifically to Dr. Henrique Bittencourt, for sending samples and data for one patient included in the study.

\section{References}

1. Sawyers CL (1999). Chronic myelogenous leukemia. New England Journal of Medicine, 340: 1330-1340.

2. Clift RA \& Anasetti C (1997). Allografting for chronic myeloid leukaemia. Baillieres Clinical Haematology, 10: 319-336.

3. Weiden PL, Flournoy N, Thomas ED, Prentice R, Fefer A, Buckner CD \& Storb E (1979). Antileukemic effects of graft versus host disease in human recipients of allogeneic marrow grafts. New England Journal of Medicine, 300: 1068-1073.

4. Kolb JH, Mittermuller J, Clemm C, Ledderooe G, Brehm G, Heim M \& Wilmans W (1990). Donor leukocyte transfusions for treatment of recurrent chronic myelogenous leukemia in marrow transplant patients. Blood, 76: 2462-2465.

5. Cullis JO, Jiang YZ, Schwarer AP, Hughes TP, Barrett AJ \& Goldman JM (1992). Donor leukocyte infusions for chronic myeloid leukemia in relapse after allogeneic bone marrow transplantation. Blood, 79: 1379-1381.

6. Jiang YZ, Barrett AJ, Goldman JM \& Mavroudis DA (1997). Association of natural killer cell immune recovery with a graft-versus-leukemia effect independent of graft-versus-host disease following allogeneic bone marrow transplantation. Annals of Hematology, 14: 16.

7. Guilhot F \& Lacotte-Thierry L (1998) Interferon- $\alpha$ : mechanisms of action in chronic myelogenous leukemia in chronic phase. Hematology and Cell Therapy, 40: 237-239.

8. Claret EJ, Alyea EP, Orsini E, Pickett CC, Collins H, Wang Y, Neuberg D, Soiffer RJ \& Ritz J (1997). Characterization of T cell repertoire in patients with graft-versus-leukemia after donor lymphocyte infusion. Journal of Clinical Investigation, 100: 855-866.

9. Verfuerth S, Peggs K, Vyas P, Barnett L, O'Reilly RJ \& Mackinnon S (2000) Longitudinal monitoring of immune reconstitution by CDR3 size spectratyping after T-cell-depleted allogeneic bone marrow transplant and the effect of donor lymphocyte infusions on T-cell repertoire. Blood, 95: 3990-3995.

10. Luznik L \& Fuchs EJ (2002). Donor lymphocyte infusions to treat hematologic malignancies in relapse after allogeneic blood or mar- row transplantation. Cancer Control, 9: 123-135.

11. Boyum A (1977). Isolation of lymphocytes, granulocytes and macrophages. Scandinavian Journal of Immunology, 5 (Suppl): 9-15.

12. Chang L, Gusewitch AG, Chritton DBW, Folz JC, Lebeck LK \& Cannarella SLN (1993). Rapid flow cytometric assay for the assessment of natural killer cell activity. Journal of Immunological Methods, 166: 45-52.

13. Jung T, Schauer U, Heusser C, Neumann C \& Rieger C (1993). Detection of intracellular cytokines by flow cytometry. Journal of Immunological Methods, 159: 197-207.

14. Bain $B$, Vas $M R$ \& Lowenstein $L$ (1964). The development of large immature mononuclear cells in mixed leukocyte cultures. Blood, 23: 108-116.

15. Deininger MWN, Goldman JM \& Melo JV (2000). The molecular biology of chronic myeloid leukemia. Blood, 96: 3343-3356.

16. Ravandi F, Kantarjian HM, Talpaz M et al. (2001). Expression of apoptosis proteins in chronic myelogenous leukemia: associations and significance. Cancer, 91: 1964-1972.

17. Pawelec G, da Silva P, Max H, Kalbacher H, Schmidt H, Bruserud O, Zugel U, Baier W, Rehbein A \& Pohla H (1995). Relative roles of natural killer- and T cell-mediated anti-leukemia effects in chronic myelogenous leukemia patients treated with interferon-alpha. Leukemia and Lymphoma, 18: 471-478.

18. Murray JS (1998). How the MHC selects Th1-Th2 immunity. Immunology Today, 19: 157-162.

19. Smit WM, Rijnbeek M, van Bergen CAM, Willemze R \& Falkenburg JHF (1998). Generation of leukemia-reactive cytotoxic T lymphocytes from HLA-identical donors of patients with chronic myeloid leukemia using modifications of a limiting dilution assay. Bone Marrow Transplantation, 21: 553-560.

20. Dazzi F, Szydlo RM \& Goldman JM (1999). Donor lymphocyte infusions for relapse of chronic myeloid leukemia after allogeneic stem cell transplant: Where we now stand. Experimental Hematology, 27: 1477-1486. 